\title{
O ciclo de vida e o desenvolvimento das microempresas: um estudo do litoral norte gaúcho
}

Lígia Margarete Mallmann ${ }^{1}$

Amanda Pereira Agliardi ${ }^{2}$

\begin{abstract}
Resumo
Da mesma maneira como acontece com seres humanos, as organizações também possuem ciclos de vida, indo do crescimento até o envelhecimento. O objetivo deste artigo foi o de verificar em que ciclo de vida está o desenvolvimento das microempresas no Litoral Norte. Para a criação do instrumento de coleta de dados, utilizouse o modelo de ciclo de vida organizacional (CVO) proposto por Adizes, que, além de fazer uma analogia com os ciclos da vida humana, busca identificar o ciclo de vida que a empresa atravessa, para poder resolver os problemas dessa fase, a fim de seguir em direção à maturidade, e, ainda, não entrar em declínio. 0 crescimento e o envelhecimento das organizações estão vinculados à flexibilidade e à controlabilidade, sendo validados por meio de um diagnóstico aplicado a um conjunto de 35 microempresas do Litoral Norte gaúcho.
\end{abstract}

Palavras-chave: Território das microempresas. Ciclo de vida. Desenvolvimento organizacional.

\begin{abstract}
Just as with humans, organizations also have life cycles, ranging from growth to aging. The objective of this article was to verify in which life cycle and how is the development of microenterprises in the North Coast. For the creation of the instrument of data collection, we used the organizational life cycle model (OLC) proposed by Adizes. That in addition, to make an analogy with the cycles of human life, seeks to identify the phase of the life cycle that the company crosses in order to be able to solve the problems pertinent to that phase and follow towards the maturity, and yet, not to decline. The growth and aging of organizations are linked to flexibility and controllability and is validated by means of a diagnosis applied to a group of 35 microenterprises in the territory of the North Coast of Rio Grande do Sul.
\end{abstract}

Keywords: Microenterprise territory. Life cycle. Organizational development.

\section{Introdução}

Assim como os organismos vivos, ao longo da vida, para crescer e se desenvolver, as organizações passam por mudanças, tanto internas quanto externas, na sua relação com o meio social no qual estão inseridas. Essas mudanças são inevitáveis, e esse caminho percorrido em direção ao amadurecimento é composto de fases, sendo cada uma delas definida por um conjunto específico de características. Amparado pelo modelo de ciclo de vida organizacional proposto por Adizes (2002), o objetivo deste artigo foi o de verificar em que ciclo de vida está o desenvolvimento das microempresas no Litoral Norte.

É importante realizar o enquadramento das organizações em seus respectivos ciclos de vida, para que se possa identificar e solucionar os problemas comuns a cada estágio, podendo, assim, a empresa passar para o próximo ciclo de desenvolvimento. Foram entrevistados 35 microempresários com microempresas sediadas no Litoral Norte gaúcho, no período de 2014 e 2015, utilizando-se amostra estratificada. As empresas foram abertas entre os anos de 1995 e 2014. Por fim, efetuou-se a análise das respostas obtidas no diagnóstico, realizando o cruzamento dos dados na forma de enquadramento sugerida no modelo Adizes (2002).

\footnotetext{
${ }^{1}$ Doutoranda e Mestre em Desenvolvimento Regional. Professora do Curso de Administração da Universidade de Santa Cruz (UNISC). ligiamallmann@unisc.br

${ }^{2}$ Bacharel em Administração Agente Local de Inovação do SEBRAE. amanda_agliardi@hotmail.com
} 
Para contextualizar o estudo, na secção 3, apresenta-se a base teórica e as definições acerca de território e microempresas. Na secção 4, encontram-se o levantamento teórico sobre os ciclos de vida organizacionais e o aprofundamento nas fases de vida descritas por Adizes (2002): namoro, infância, toca-toca, adolescência, plenitude, estabilidade, aristocracia, burocracia incipiente, burocracia e morte e três anomalias - mortalidade infantil; cilada do fundador; divórcio, este compreende o envelhecimento precoce e o empreendedor não realizado.

Os resultados obtidos nas entrevistas são apresentados na secção 5, juntamente com uma analogia entre o comportamento humano e o desenvolvimento da gestão organizacional nas empresas pesquisadas.

\section{Enquadramento no modelo metodológico}

Para este estudo, utilizou-se o modelo ciclo de vida organizacional proposto por Adizes (2002) para a coleta de dados secundários. Outra ação metodológica constituiu-se numa pesquisa de campo, considerando a investigação empírica, realizada no local onde ocorre ou ocorreu um fenômeno, incluindo a aplicação de 35 (trinta e cinco) questionários (Anexo A), com perguntas abertas e fechadas, entrevistas e observação participante, no Litoral Norte, no período de 2014 e 2015. Segundo Mattar (1999), o estudo de campo deve ser utilizado quando se tem interesse em conhecer o inter-relacionamento entre as diversas variáveis que ocasionam um fenômeno.

Há um momento em que o público-alvo se divide em subconjuntos denominados estratos, para a representação mais homogênea dos elementos. A amostra estratificada caracteriza-se pela seleção aleatória de um grupo de amostras de cada subgrupo de uma população. Essa é uma técnica mais refinada de coleta de dados, por assegurar a representação mais adequada para cada tipo de subpopulação, permitindo a redução de erros na amostra (COLAUTO; BEUREN, 2004).

Com base em Gil (1999), optou-se pela amostragem estratificada de microempresas de prestação de serviços, do comércio, da indústria de diversas atividades, de forma aleatória e por conveniência. Empresas foram abertas entre os anos de 1995 a 2014. O detalhamento está explicitado nas análises dos resultados e conforme o enquadramento no modelo metodológico Adizes ${ }^{3}$.

\footnotetext{
${ }^{3}$ Ichak Adizes é o fundador do Instituto ADIZES, em Santa Mônica, Califórnia. Foi o criador da metodologia de diagnóstico e terapêutica para mudanças organizacionais e culturais que leva o seu nome. O método Adizes vem sendo aplicado com crescente eficácia e eficiência em organizações dos mais diversos países, entre os quais Estados Unidos, Brasil, Groenlândia, Malásia, Israel, Espanha, México e Noruega. Essas organizações empregam as mais variadas tecnologias, e incluem desde bancos a cadeias de restaurantes, desde igrejas a burocracias governamentais. Mil e duzentas páginas de manuais e cem horas de fitas de vídeo e áudio documentam a metodologia aplicada em toda a parte do mundo. Adizes é renomado conferencista e autor, fala quatro idiomas, já palestrou em mais de 35 países. É o autor de Industrial Democracy Yugoslav style (Free Press e Columbia University, 1971); de Self Management, em parceria com Elisabeth Man Borgese (ABC Clio Press e Center for the study of Democratic Institutions, 1975); de Como Resolver as Crises de Antigerência (Pioneira, 1987), todas obras disponíveis através do Instituto Adizes. Além disso, já escreveu mais de quarenta artigos para periódicos especializados e revistas. É livre-docente da Anderson Graduate Scholl of Management da Universidade da Califórnia, Los Angeles, e tem sido professor visitante das Universidades Stanford, Tel Aviv e Hebraica de Jerusalém.
} 


\subsection{Enquadramento no modelo Adizes}

Como parâmetro de modelo metodológico, foi utilizado o ciclo de vida organizacional proposto por Adizes (2002). Segundo este analista e consultor empresarial, as organizações, da mesma forma que os organismos vivos, possuem ciclos de vida. Elas enfrentam os embates e as dificuldades normais que existem em cada estágio do ciclo de vida organizacional, e também os problemas usuais de transição ao ingressarem numa nova fase do seu desenvolvimento.

O método Adizes de gerência descreve os problemas que uma organização enfrenta em cada estágio do ciclo de vida organizacional: do namoro, da infância, do toca-toca, da adolescência, da plenitude, da estabilidade, da aristocracia, da burocracia incipiente, da burocracia e morte ${ }^{4}$ e três anomalias - mortalidade infantil, cilada do fundador e divórcio, este compreende o envelhecimento precoce e o empreendedor não realizado. Segue o modelo teórico adotado para este estudo.

\section{Figura 1 - Ciclo de vida Adizes}

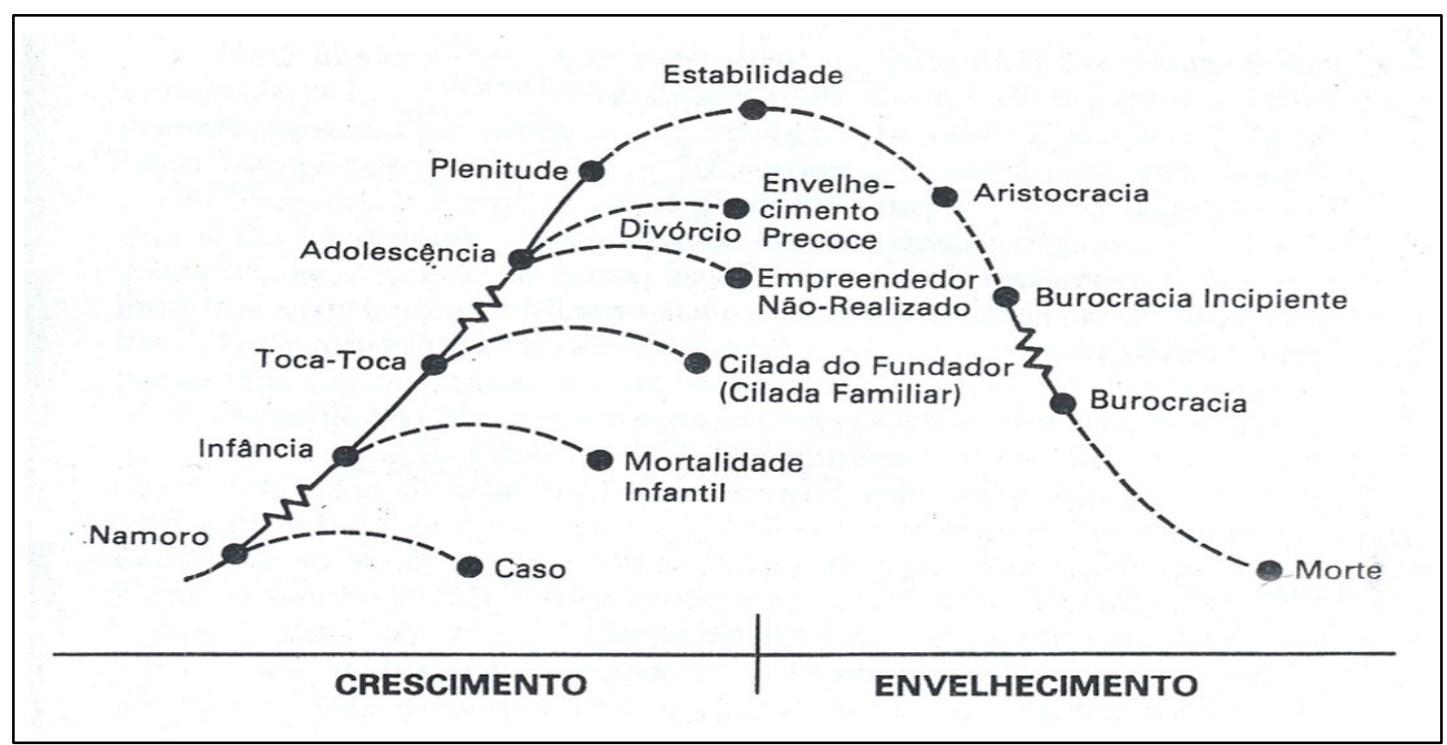

Fonte: Adizes (2002, p. 87).

Cabe ressaltar que o estudo desta investigação começa no segundo estágio, da Infância, tendo em vista que o primeiro estágio, do Namoro, é o sonho do fundador, mas que ainda não tem forma, ou seja, a instituição ainda não foi criada. Há grande agitação e entusiasmo. São realizados planos, e imagina-se o sucesso que pode ser atingido, mas, quando os planos não saem do papel, a instituição não nasce, e o projeto torna-se apenas um "caso" passageiro. Já quando os planos são colocados em prática, a organização é aberta.

\footnotetext{
${ }^{4}$ Com base na obra de Adizes (2002), serão citadas - no item 4. Ciclo de vida organizacional - as principais características de cada uma das fases do ciclo de vida organizacional, com o objetivo de proporcionar ao leitor deste estudo uma visão panorâmica do modelo, considerando que o mesmo se constitui em parte fundamental da análise proposta.
} 
A mesma confirmação de compromisso ocorre de forma análoga no namoro que precede o casamento. Esse processo de firmar compromisso é acompanhado de muita empolgação, muito entusiasmo e muita emoção. Num casamento, uma relação de amor é necessária para se firmar um compromisso. No ciclo de vida da empresa, o fundador precisa "apaixonar-se" pela ideia do negócio que está concedendo. Mais tarde, quando a empresa já tiver nascido, é o seu amor por esse recém-nascido que preservará a sua motivação durante os momentos difíceis da Infância. Para Adizes (2002), quando a empresa é aberta, entra no estágio denominado infância, fase pela qual se optou por iniciar o estudo, já com a microempresa aberta. Chama-se a atenção que o modelo Adizes (2002) faz uma analogia com o comportamento humano, e não com a vida cronológica.

\section{0 território e as microempresas}

O território é entendido com o sentido que lhe é dado por Raffestin (1993) cuja principal contribuição é a proposição de uma abordagem relacional do território, na qual ele é indissociável do poder. Tomando esta proposição como referência, partimos do princípio de que toda relação de poder desempenhada por um sujeito no espaço produz um território. 0 que, de acordo com Santos (1994), é "[...] sinônimo de espaço geográfico", onde se materializam as relações entre indivíduos e grupos sociais, constituindo-se em locus de exercício de poder, pois supõe assimetrias na posse dos recursos e das estratégias para seu exercício (CASTRO, 2005). Dessa forma, Santos (2003) esclarece que o território é o chão e mais a população, isto é, uma identidade, o fato e o sentimento de pertencer àquilo que nos pertence. O território é a base do trabalho, da residência, das trocas materiais e espirituais e da vida, sobre os quais ele influi.

Quando se fala em território, deve-se, pois, de logo, entender que está falando em território usado, utilizado por uma população. Neste sentido, estamos citando o território usado pelas microempresas sediadas no Litoral Norte gaúcho. O Corede ${ }^{5}$ Litoral é composto por 21 (vinte e um) municípios, com uma população de 323.112 habitantes (FEE, 2016). Conforme o site Empresometro (2016), o Estado do Rio Grande do Sul (RS), em 2016, registrou 1.083.474 micro e pequenas empresas (MPE's), representando 7,3\% do total dessas empresas no Brasil. 0 Corede Litoral possui 40.964 MPE's registradas, representando 3,78\% em relação ao RS; já o município de Capão da Canoa/RS possui 8.055 MPE's, o que representa 19,66\% das MPE's do Corede Litoral. Neste território, diversas atividades são desempenhadas, sendo que, para este estudo, as principais são as do comércio de um modo geral.

Portanto, é relevante a definição de MPE's. Para Dornelas (2014), numa definição generalizada, ainda que pouco precisa, MPE's são um tipo de empresas com um número reduzido de trabalhadores, nas quais o faturamento é modesto. Não há unanimidade na delimitação do segmento das MPE's. Observa-se, na prática, uma variedade de critérios para a sua definição, tanto por parte da legislação específica como por parte de instituições

\footnotetext{
${ }^{5}$ Conselho Regional de Desenvolvimento do Governo do Rio Grande do Sul.
} 
financeiras oficiais e órgãos representativos do segmento: ora se baseiam no valor do faturamento, ora no número de pessoas ocupadas, ora em ambos. A Lei no 123/2006 regulamenta as MPE's, e a Lei no 128/ 2008 regulamenta o Microempreendor Individual - MEl.

A definição de MPE's pode ser vista sob, no mínimo, dois aspectos: conforme o faturamento e segundo o número de funcionários.

Classificação conforme o faturamento:

- $\mathrm{MEI}=$ até $\mathrm{R} \$ 60.000,00$ a.a;

- MICROEMPRESA = até 360.000,00 a.a;

- $\operatorname{EPP}($ Empresa de pequeno porte) $=$ até $3.600 .000,00$ a.a.

Classificação por número de funcionário:

- $\mathrm{MEI}=$ um funcionário com recebimento de um salário mínimo ao mês;

- MICROEMPRESA = * indústria e construção civil: até 19 funcionários;

* comércio e serviços: até 09 funcionários

- EPP = * indústria e construção civil: de 20 a 99 funcionários;

* comércio e serviços: de 10 a 49 funcionários

Para Pagliuso, Cardoso e Spiegel (2010), as organizações sempre tiveram que ajustar as competências de suas pessoas às suas necessidades de operação. Na década de 1990, o ambiente de negócios tornou-se mais complexo. Fenômenos econômicos e sociais de alcance mundial estão reestruturando o ambiente empresarial. A globalização da economia, alavancada pela tecnologia da informação e da comunicação, é uma realidade presente. As chamadas novas tecnologias, bem como as novas formas de organização do trabalho, têm colocado os métodos tradicionais de gestão das empresas em controvérsia. Nesse sentido, além de todos os tipos de conflitos, as microempresas encontram-se sobre o território, que, segundo Santos (1994), é a base do trabalho, da residência, das trocas materiais e espirituais e da vida. Portanto, também sofrem a ação de seus estágios desde o seu nascimento até a sua morte.

\section{Ciclo de vida organizacional}

A evolução das organizações, em termos de modelos estruturais e tecnológicos, tendo as mudanças e o conhecimento como novos paradigmas, tem exigido uma nova postura nos estilos pessoais e gerenciais, voltada para uma realidade diferenciada e emergente. Porém, o grande desafio vem sendo a capacidade e a competência diária das organizações para enfrentarem e se adaptarem a essas mudanças, levando todos os seus níveis hierárquicos e funcionais, da alta gerência ao piso de fábrica, a incorporarem novos modelos, métodos, 
técnicas, instrumentos, atitudes e comportamentos necessários às mudanças, às inovações e à sobrevivência saudável e competitiva no mercado (DRUCKER, 1995).

\begin{abstract}
As empresas têm um papel claro a desempenhar na sociedade a que servem: prover produtos de valor (utilidades) que irão satisfazer às necessidades de um grupo representativo de pessoas (clientes), praticando padrões de comportamento (conduta) aceitos pela sociedade. Além disso, as empresas têm obrigações internas a cumprir: satisfazer às expectativas de seus empreendedores e colaboradores (realizações) e ter um comportamento (conduta) coerente com suas convicções, crenças e valores. Esses objetivos, que constituem a razão de ser das empresas válidas, são atendidos através da execução de um conjunto diversificado e complexo de atividades que compõem a tarefa empresarial a cargo da administração (ARANTES, 1998, p. 85).
\end{abstract}

Para Mintzberg, Ahlstrand e Lampel (2000), no mundo empresarial, em qualquer parte do planeta, as pessoas estão sentindo o reflexo de novas transformações, seja pelo cenário externo, como o declínio de antigas empresas multinacionais e o surgimento de novos competidores, seja pelos diversos outros fatores internos e externos que influenciam o administrador no seu cotidiano. As mudanças enfrentadas pelos empresários são significativas, sejam elas quanto ao perfil dos clientes ou fornecedores, produtos e serviços; tudo isso gera mudanças na gestão empresarial das grandes, das médias e das MPE's. Atualmente, gerir envolve uma gama muito mais abrangente e diversificada de atividades do que no passado. Para Mallmann (2008), o empresário precisa estar apto a perceber, refletir, decidir e agir em condições totalmente diferentes das de antigamente. Nesse sentido, há diversos modelos teórico-metodológicos para o enquadramento do estudo nos ciclos de vida de uma organização, sendo elas MEI, Micro, EPP,Média ou Empresa de Grande Porte. Para este estudo, foi utilizado o modelo Adizes, que é baseado em dois fatores: "flexibilidade" e "controlabilidade".

\title{
4.1 Ciclo de vida organizacional Adizes
}

Para entender o processo de crescimento e envelhecimento das organizações, é conveniente comparar esses fatores com o comportamento de um ser humano nas diferentes fases da vida (ADIZES, 2002). Assim como os bebês, as organizações, quando jovens, são bastante flexíveis, porém nem sempre facilmente controláveis. Ao envelhecerem, ambos diminuem a flexibilidade e aumentam a controlabilidade. Por outro lado, diferentemente do ser humano, tamanho e tempo não são causas de crescimento e envelhecimento das organizações. Uma empresa pode ser grande, tradicional e jovem, enquanto outra pode ser pequena, sem tradição e velha. Para o autor, a diferenciação entre empresas jovens e velhas está no comportamento. Enquanto as primeiras possuem grande propensão à mudança, são imprevisíveis e com baixo nível de controle, as outras possuem comportamento controlável, inflexível e dificilmente modificável.

Em cada estágio do ciclo de vida, tanto empresas quanto pessoas enfrentam diversos problemas, e não é correto pensar que esses problemas acabarão. À medida que uns são 
resolvidos, outros são gerados. Deve-se tomar cuidado para identificar se esses problemas são normais ou não para determinada fase da vida.

A seguir, explicitaremos os ciclos de vida e as patologias do modelo Adizes. As possibilidades de respostas oferecidas para todas as perguntas realizadas foram sim e não. No primeiro caso, procurou-se verificar, ainda, se o processo era formal ou informal. No segundo caso, buscou-se averiguar se o empresário conhecia ou não o assunto em questão. Dessa forma, caracteriza-se em que ciclo de vida ou patologia a empresa se encontra (ADIZES, 2002).

\section{Estágio: a infância}

A infância: nesse estágio de vida da organização, o que conta não é o que uma pessoa pensa, mas o que ela faz. Em uma analogia com a vida humana, é necessário, na infância, leite e amor dos pais; na organização, uma infusão periódica de dinheiro (capital de giro), pois, se não obtiver o suficiente, ela morre. Também o compromisso do fundador, já que, se for pouco, a organização também pode perecer.

A seguir as questões que identificam este ciclo:

- a empresa prioriza o produto?

- existe muita devolução de mercadoria e/ou retrabalho?

- geralmente é necessário trabalhar nos finais de semana e/ou feriados?

- existe controle formal de contas a pagar/receber?

- há livro-caixa formal?

- existe planejamento financeiro (objetivos/metas)?

Segundo o modelo teórico adotado, nesse estágio da vida da organização, pode ocorrer uma patologia denominada de Mortalidade Infantil. Análogo à vida humana, o não cuidado com a criança a leva a adoecer e, consequentemente, à morte. Na empresa, o não monitoramento do giro das contas a receber, a pagar e do estoque pode destruir a liquidez da organização criança e gerar essa patologia. Para demonstrá-la, elaboraram-se as seguintes perguntas:

- o empresário percebe muita alienação pelas intervenções externas?

- o empresário centraliza todas as decisões da empresa?

- o empreendedor recebe amparo/apoio da família para desempenhar as suas atividades empresariais?

- a empresa possui liquidez para honrar seus compromissos em dia? 


\section{Estágio: o toca-toca}

A organização parece que não só está sobrevivendo, como também florescendo. Como um bebê que começa a engatinhar: ele quer ir a toda a parte, não vê problemas, só oportunidades. Numa analogia com a vida humana, nesse ciclo, a empresa também passa por períodos de crescimento, assim como um garoto de dois anos, cujos pais não podem perdê-lo de vista um instante sequer, pois o garoto não para de se meter em encrencas, das quais dificilmente conseguirá sair sozinho. A organização toca-toca requer o mesmo tipo de atenção, e, se o sucesso do presente fez o fundador esquecer as dificuldades da infância, realizou-se um dos seus sonhos, e, se um sonho pôde se realizar, por que não outros? As perguntas que mencionam características desse ciclo de vida são:

- falta pessoal treinado (técnico) na empresa?

- existe aumento expressivo nas vendas, sem esforço extra?

- há posto de venda e/ou filiais em outras localidades?

- os colaboradores possuem liberdade para tomar decisões organizacionais?

- há planejamento organizacional?

Neste estágio de vida da organização, pode ocorrer outra patologia, esta denominada de cilada do fundador ou cilada familiar. Nessa fase, em uma analogia com a vida humana, se o garoto sair sozinho, pode gerar problemas para os pais e para os familiares. Nessa fase, a empresa enfrenta dificuldade para descentralizar o poder e a liderança: se o fundador não está sempre presente, ninguém mais tem o direito, o arrojo ou a coragem de tomar decisões. A cilada do fundador significa que, se o fundador morrer, a empresa talvez morra também. A cilada do fundador pode ainda transformar-se numa cilada familiar, quando algum membro da família assume a empresa pelo simples fato de ser dono dela, e não por sua competência ou experiência. Para demonstrar esta patologia, as seguintes perguntas foram elaboradas:

- a empresa conta com regras e procedimentos, mas geralmente o empresário necessita violá-las?

- o empresário já pode investir em carros, barcos, viagens de lazer e/ou outras formas de entretenimento?

- a empresa conta com gerente profissional, administrativo ou herdeiros na sucessão gerencial/administrativa?

- existe facilidade de o fundador delegar atribuições para seus colaboradores? 


\section{Estágio: a adolescência}

A empresa é, de fato, como um adolescente tentando estabelecer sua independência da família. As atitudes comportamentais da organização adolescente são o conflito e a inconsistência. Referente a este ciclo, foram elaboradas as perguntas:

- os colaboradores são chamados por apelidos?

- existe alta rotatividade dos gerentes e/ou encarregados?

- existe sistema de cumprimento de metas da empresa e dos colaboradores individualmente?

- a empresa utiliza e monitora o fluxo de caixa?

- a empresa possui sistema administrativo estruturado?

- há profundidade gerencial?

Neste estágio de vida da organização, encontra-se a última patologia, o divórcio, que compreende o envelhecimento precoce e o empreendedor não realizado, mencionada no modelo Adizes (2002). A crise que se instala no final da adolescência é típica de um conflito de liderança. Nessa fase, análoga à vida humana, a empresa ainda tem muita energia. As empresas, na fase de declínio (perto da morte), têm interesse em fazer fusão ou comprá-la, o que gera o divórcio com o envelhecimento precoce e torna a empresa burocratizada. 0 fundador não se realiza. Com problemas de controle e alta rotatividade de pessoal, desilude-se e vende a empresa. Para demonstrar esta patologia, elaborou-se as seguintes perguntas:

- existe alta rotatividade de pessoas, especialmente dos indivíduos mais empreendedores?

- o empresário precisa repensar a sua forma de gerir, delegar autoridade e transpor metas?

- há sistema de remuneração formal?

- as diretrizes e/ou normas são sempre cumpridas pelos colaboradores da empresa?

\section{Estágio: a plenitude}

Esta é a melhor fase da empresa. Em uma analogia com a vida humana, é a de uma pessoa feliz e realizada na sua vida pessoal e profissional. Entre as principais características, destacam-se sistemas e estrutura organizacional funcionais, visão e criatividade institucionalizadas, orientação para os resultados e satisfação das necessidades dos clientes pela organização. Para este quesito, ordenou-se as seguintes questões:

- a empresa possui indicadores de crescimento das vendas e da lucratividade?

- a organização possui orientação para satisfazer às necessidades dos clientes? 
- existe pouca discrepância entre o orçamento previsto e o realizado?

- as compras são efetuadas conforme as necessidades da empresa?

- o local de trabalho é improvisado conforme o crescimento da empresa?

- os equipamentos (máquinas) pertencentes à empresa recebem manutenção somente quando estragam?

\section{Estágio: a estabilidade}

Nesta fase, a empresa ainda está forte, mas vai perdendo sua flexibilidade, está chegando ao fim do crescimento e começando a declinar. Análogo à vida humana, a pessoa se acomodou, não se atualiza, não estuda e nem tem mais criatividade, tendo medo, inclusive, de perder o que conquistou. Para esse ciclo, criou-se os seguintes questionamentos:

- ultimamente a empresa está diminuindo o valor investido em marketing?

- existe acompanhamento rigoroso sobre o retorno do capital investido?

- há formalidade no tratamento e no vestir de seus dirigentes e colaboradores?

- as mudanças são sempre bem-vistas e/ou aceitas?

- há grande expectativa de conquistar novos mercados, tecnologias e regiões inexploradas?

- os colaboradores disponibilizam grande parte de seu tempo para atender a clientes e/ou fornecedores?

\section{Estágio: a aristocracia}

A organização é menos ativa e mais passiva diante das oportunidades a longo prazo. Em uma analogia com a vida humana, nesta fase, a pessoa é conservadora no pensar, ou seja, na aparência, continua ostentando como se ainda tivesse muitos recursos, não quer perder o "status". Nesse contexto, os seguintes questionamentos são pertinentes:

- a empresa investe e/ou prioriza sistemas de controle, benefícios e instalações para o conforto organizacional?

- há procura para aquisição de suas ações e/ou interessados em sociedades na empresa?

- a empresa pensa em adquirir outras empresas para obter novos produtos e mercados?

- a organização ajusta os preços de forma a compatibilizá-los com os custos?

- existe otimização do espaço físico da empresa? 


\section{Estágio: a burocracia incipiente}

$\mathrm{Na}$ burocracia incipiente, quando os maus resultados se tornam, afinal, evidentes, ao invés de lutarem contra os concorrentes, como deveriam, os gerentes começam a lutar entre si, numa verdadeira paranoia. Análogo à vida humana, as pessoas não conseguem encontrar soluções, e, sim, apenas culpados pela situação ruim, que agora não dá mais para disfarçar. As questões elaboradas nesse contexto foram:

- o fluxo de caixa, outrora positivo, agora torna-se negativo?

- a empresa se disponibiliza a vender sua reputação (tradição, marca, conhecimento)?

- há muito conflito, muitas "facadas" pelas costas, muitas brigas internas?

- a empresa é organizada?

- a capacidade criativa da empresa está dirigida à criação de produtos melhores?

- há formulação de estratégias de marketing?

\section{Estágio: a burocracia e morte}

No estágio burocrático, a empresa não gera recursos próprios em grau suficiente. Ela justifica sua existência não pelo fato de funcionar bem, mas simplesmente pelo fato de existir. A morte só é afastada através de sistemas artificiais de vida. Numa analogia com a vida humana, a situação é a mesma que a de uma pessoa hospitalizada, sobrevivendo por aparelhos. Neste ciclo, as questões evidentes são as seguintes:

- seus colaboradores desempenham outras atividades paralelas?

- a empresa necessita de repasse de recursos financeiros do governo para cumprir suas obrigações?

- a empresa está no mercado porque detém algum tipo de monopólio?

- a empresa gera recursos próprios para sua manutenção?

- a empresa tem compromisso/comprometimento com seus clientes?

- seus sistemas funcionais são práticos e eficientes?

Após a abordagem dos principais temas e conceitos, são explicitados os resultados da pesquisa.

\subsection{Análise e discussão do desenvolvimento organizacional}

Efetuada a análise das respostas obtidas no questionário, realizado o cruzamento dos dados na forma de enquadramento no modelo Adizes (2002), objetivou-se responder a que ciclo de vida corresponde o desenvolvimento das 35 (trinta e cinco) microempresas do Litoral Norte gaúcho estudadas no período de 2014 e 2015. Conforme Santos (1994), território é “[...] 
sinônimo de espaço geográfico", onde se materializam as relações entre indivíduos e grupos sociais, constituindo-se em locus de exercício de poder. Dessa forma, Santos (2003) esclarece que o território é o chão e mais a população, isto é, uma identidade, o fato e o sentimento de pertencer àquilo que nos pertence. $O$ território é a base do trabalho, da residência, das trocas materiais, espirituais e da vida. Nesse sentido, o enquadramento proposto mostra o desenvolvimento e o comportamento em cada ciclo de vida, conforme o modelo metodológico Adizes. Para este estudo, foram pesquisadas empresas de diversas atividades (Figura 2, inserida na próxima página).

O método Adizes permite a análise de qualquer atividade que a empresa desempenhe e permite fazer uma analogia entre o comportamento humano e o desenvolvimento da sua gestão organizacional. A Figura 2 explicita algumas atividades desempenhadas Litoral Norte gaúcho. O que fica explicitado é que $97,14 \%$ das atividades desenvolvidas são do segmento do comércio e da prestação de serviços, uma característica desse território.

A Figura 3 (inserida na próxima página) mostra o percentual de cada um dos nove ciclos de vida e das três patologias do modelo metodológico, observados nas 35 (trinta e cinco) empresas estudadas, as quais foram enquadradas no modelo Adizes, conforme as respostas dos questionários, em entrevista.

Figura 2 - Participação relativa das atividades empresarias

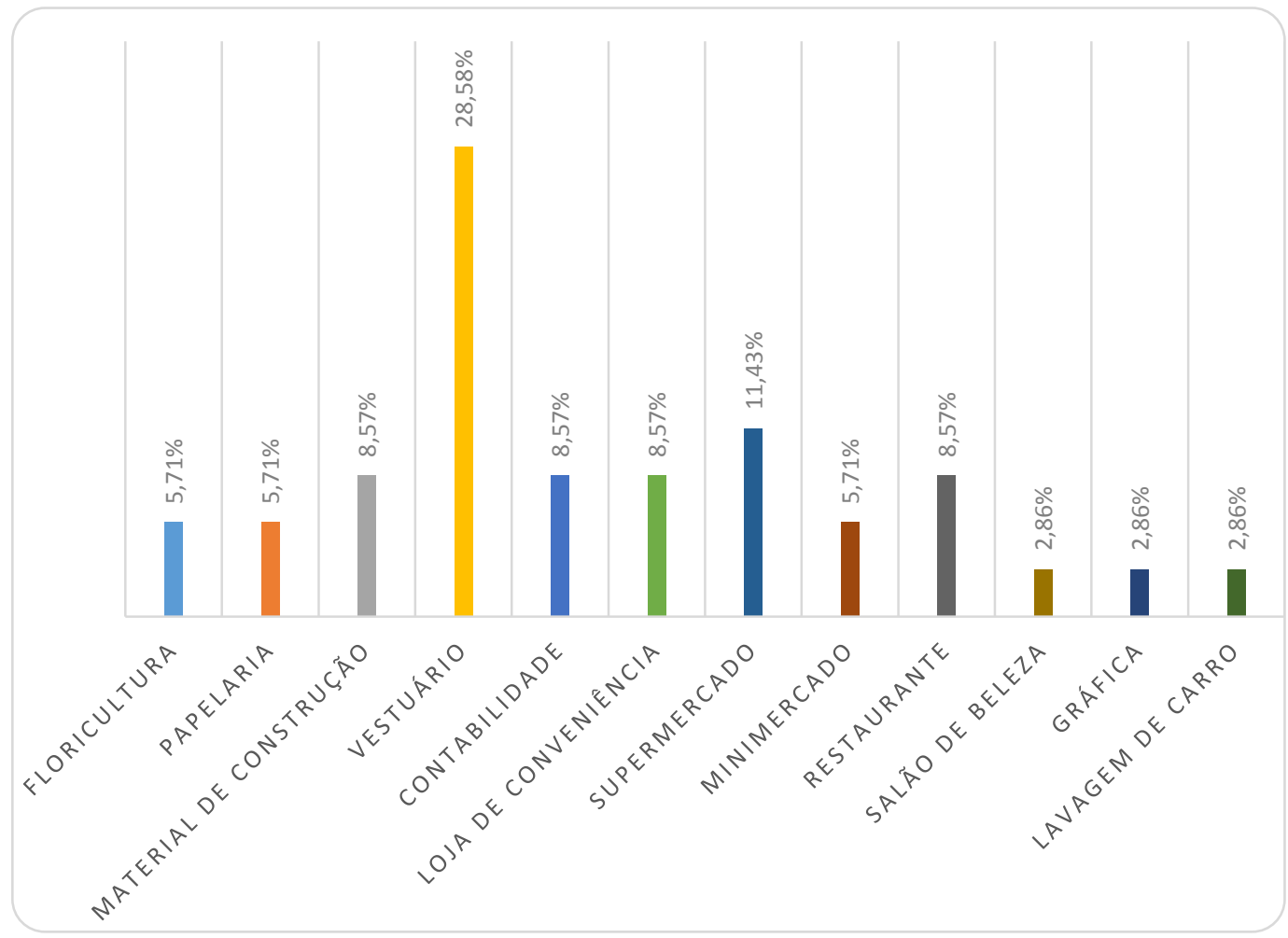

Fonte: Elaborado pelas autoras, com base na pesquisa (2016). 
Figura 3 - Ciclo de vida das empresas, modelo metodológico Adizes

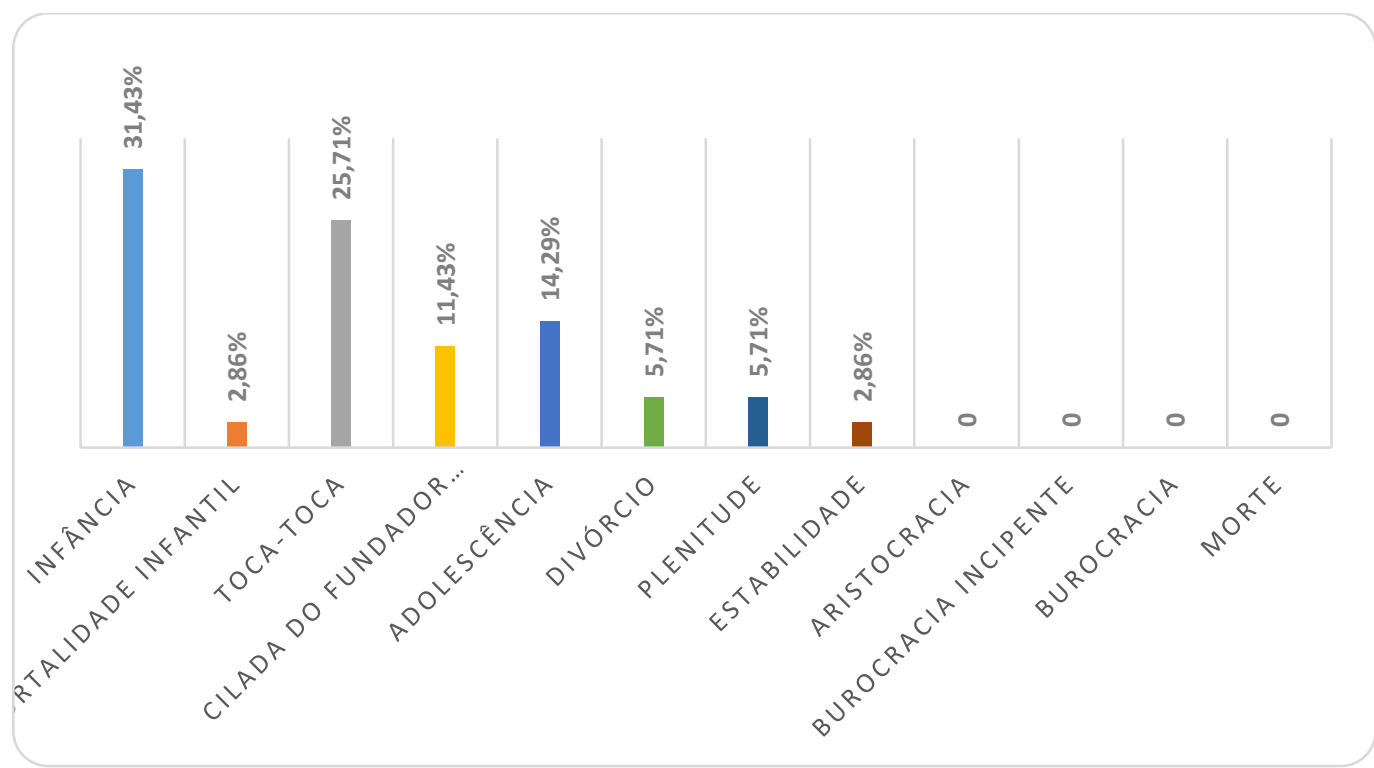

Fonte: elaborado pelas pesquisadoras, com base na pesquisa, 2016

No ciclo de vida da Infância, encontram-se 31,43\% das empresas pesquisadas, as quais possuem pouca disponibilidade de recursos financeiros para formar o seu capital de giro, falta de diretrizes e normas, ambiente pessoal e hierarquia informal. Segundo Adizes (1998; 2002), assim como uma criança de colo, nesta fase, a empresa é vulnerável e inconsistente, sobrevivendo em meio a crises. Devido à precariedade de capital de giro e de pessoal competente, o fundador da empresa deve ter muito cuidado para não perder o controle sobre ela, ou sentir-se alienado por ela, e, assim, acabar na patologia denominada Mortalidade Infantil.

Das empresas estudadas, 2,86\% não conseguiram passar a fase da Infância de forma saudável e encontram-se na Mortalidade Infantil. Conforme Adizes (1998 e 2002), isso ocorre porque a organização não consegue cumprir com seus compromissos, tem perdas financeiras relevantes, intervenções externas que impactam a empresa bruscamente, e perda de controle de decisão pela gerência. Dessa forma, o fundador delega poder prematuramente, fazendo com que a administração seja desqualificada.

Quando a empresa consegue superar as dificuldades do ciclo da infância e passar pelas crises, chega a outro ciclo de vida, o do toca-toca, fase em que se encontram $25,71 \%$ das empresas pesquisadas. Segundo Adizes (1998; 2002), assim como uma criança, a empresa está crescendo de forma muito acelerada e só vê as oportunidades, e não o perigo. O espaço tornase escasso, sendo comum a empresa abrir outros pontos de negócios, do mesmo segmento de atuação ou em outros, na mesma cidade ou em outros municípios. Entretanto, existe um risco de o fundador deslumbrar uma realidade diferente da atual vivida pela empresa, e, assim, cair na patologia denominada de Cilada do Fundador ou Cilada Familiar.

Nesta patologia Cilada do Fundador ou Cilada Familiar, encontram-se 11,43\% das empresas estudadas. Portanto, essa é uma etapa muito difícil para o fundador, porque aqui ele tem que descentralizar o poder, já que a empresa cresceu, e o fundador não consegue 
controlar tudo sozinho. Entretanto, essa não é uma tarefa fácil, e muitos fundadores passam a delegar autoridade para os gerentes, a fim de que estes tomem as decisões. Porém, como não querem perder o controle, o poder fica como um "braço mecânico": ora o gerente toma a decisão, ora o fundador, e a empresa não tem gestão gerencial. A Cilada do Fundador pode tornar-se uma Cilada Familiar, se a escolha for feita levando em consideração quem tem mais direito de propriedade, ao invés de escolher quem tem mais qualificação para assumir o cargo.

No ciclo denominado Adolescência, a principal preocupação da empresa é com o lucro, e $14,29 \%$ das empresas pesquisadas encontram-se neste ciclo. Comparando esse estágio aos da vida humana, trata-se de um adolescente tentando estabelecer sua independência da família. As atitudes comportamentais do adolescente são o conflito e a inconsistência. É nessa etapa do ciclo de vida organizacional que se encontra a última patologia mencionada no modelo Adizes (1998; 2002), o divórcio. A patologia ocorre quando o conflito resulta numa perda crítica da confiança e do respeito mútuos entre aqueles que detêm o controle formal e informal do processo decisório da empresa. Após analisar as características típicas deste estágio, concluiuse que $5,71 \%$, do universo pesquisado encontram-se aí. Nesse caso, a maioria dos empresários e/ou gestores possui conhecimento específico das ferramentas de gestão empresarial, podendo superar essas dificuldades e passar para o estágio seguinte.

A partir do estágio da Plenitude, não há mais patologias, e a maior preocupação da empresa é com as vendas e o lucro. Usando o mesmo critério de análise para o enquadramento no modelo Adizes, constatou-se que 5,71\% das empresas analisadas alcançaram esta fase de vida organizacional. A implicação maior neste estágio, que é considerado o apogeu do ciclo de vida organizacional, é a baixa dos índices do seu desempenho. Nessa fase, deve-se prestar mais atenção nos clientes, nos fornecedores, nos novos entrantes e também em produtos substitutos, porque, de certa forma, todos são competidores no mercado, sendo que a empresa Plena deve sempre monitorar seus índices de desempenho para não passar para o estágio seguinte. Mas, se isso for inevitável, numa analogia com a vida humana, também é a melhor fase da vida, quando a pessoa alcança a maturidade, o equilíbrio, agindo com moderação e ainda tendo a possibilidade de realizar mais conquistas.

O ciclo denominado Estabilidade é o último do crescimento, mas também é considerado o início do declínio no modelo teórico adotado para este estudo. A maior preocupação da empresa, nesta fase, é proteger o que conquistou. Concluiu-se que $2,86 \%$ encontram-se neste estágio, confirmando-se que a maior preocupação da empresa é manter e proteger o seu "status". Ao realizar-se uma analogia entre a vida organizacional e a vida humana, percebe-se que, no estágio da Estabilidade, já se conquistou o que foi possível, e agora há a preocupação em conservar e manter essas conquistas; para isso, negocia-se; fazem-se pactos e não se permite que outros nos superem no nosso núcleo. E surge o medo da descida.

Os estágios seguintes do ciclo de vida organizacional Adizes (1988; 2002) são de declínio. Verificou-se que não há empresas, entre as pesquisadas, nestes estágios. Portanto, são apenas explicitadas as principais características dos estágios seguintes do modelo teórico adotado para este estudo e sua analogia com a vida humana. O comportamento de uma 
organização no estágio da Aristocracia, de forma análoga à vida humana, é o que prevalece em casamentos que começam a ruir. O casal pode tentar solidificar a relação firmando novos compromissos, seja tendo um filho, ou comprando uma casa nova. Mas o comprometimento já se encontra abalado. A Burocracia Incipiente torna-se evidente com as grandes dificuldades de fluxo de caixa negativo, e, quando isso acontece, as pessoas começam a lutar entre si num "salve-se quem puder".

Numa analogia com a vida humana, é o comportamento de quem quer continuar sobrevivendo, mesmo que a morte seja inevitável. Os últimos estágios deste ciclo de vida organizacional são a Burocracia e a Morte. A empresa não gera recursos próprios em grau suficiente, embora conheça todas as regras. Ao se estabelecer um comparativo dessa fase com as da vida humana, o início da burocracia é semelhante ao de uma pessoa idosa. Nas palavras de Adizes (2002, p. 89), "[...] uma pessoa mais idosa consegue lembrar-se de 1936 como se fosse ontem, mas muitas vezes não se recorda do que tomou no café da manhã". E a morte para uma pessoa é só uma questão de tempo.

\section{Considerações finais}

Assim como os seres humanos possuem fases em sua vida: nascimento, crescimento, desenvolvimento e morte, as empresas também possuem seus ciclos. O estudo aponta para a importância de o empreendedor identificar a fase em que a organização se encontra e, assim, ter a capacidade de resolver os problemas comuns a essa fase, para atingir a maturidade e ali permanecer. $O$ fato de ser feita uma analogia entre a vida humana e as organizações facilita o entendimento das fases de desenvolvimento da empresa por parte do empreendedor, que passa a compreender desde elementos internos, como estilo de gestão, até questões relacionadas ao mercado externo.

O modelo de Adizes permitiu a elaboração de um instrumento de pesquisa com o qual foi possível verificar o ciclo de vida de 35 microempresas do Litoral Norte gaúcho. A aplicação do instrumento indicou que as questões formuladas são de fácil entendimento, e a análise das respostas descreve a atual situação da organização diagnosticada, sendo possível, dessa forma, além de verificar em que ciclo a organização está, quais decisões são cabíveis e podem ser tomadas.

\section{Referências}

ADIZES, Ichak. Os ciclos de vida das organizações: como e por que as empresas crescem e morrem e o que fazer a respeito. Tradução de Carlos A. Malferrari. São Paulo: Pioneira, 1988.

- Os ciclos de vida das organizações: como e por que as empresas crescem e morrem e o que fazer a respeito. Tradução de Carlos A. Malferrari. 2. ed. São Paulo: Pioneira, 2002.

ARANTES, Nélio. Sistemas de gestão empresarial: conceitos permanentes na administração de empresas válidas. São Paulo: Atlas, 1998. 
CASTRO, Inácio de E. de. Geografia e Política. Rio de Janeiro: Bertrand Brasil, 2005.

COLAUTO, Romualdo Douglas; BEUREN, Ilse Maria. Coleta, Análise e Interpretação dos Dados. In: BEUREN, Ilse Maria (Org.). Como elaborar trabalhos monográficos em contabilidade: teoria e prática. 2. ed. São Paulo: Atlas, 2004.

DORNELAS, José Carlos Assis. Empreendedorismo: transformando ideias em negócios. 5. ed. Rio de Janeiro: Empreende/LTC, 2014.

DRUCKER, Peter F. Administrando em tempos de grandes mudanças. São Paulo: Pioneira, 1995.

EMPRESOMETRO. Dados estatísticos. Disponível em: <http://empresometro.cnc.org.br/Estatisticas>. Acesso em: 23 jun. 2016.

FEE. Fundação de Economia e Estatística. (2014 - 2016) - Perfil socioeconômico. Disponível em: <http://www.fee.rs.gov.br/perfil-socioeconomico/coredes/detalhe/corede=Litoral>. Acesso em: 17 jun. 2016.

MALLMANN, Lígia Margarete. Gestão Empresarial: o papel das micro e pequenas Empresas no desenvolvimento do Vale do Rio Taquari/RS. Dissertação (Programa de Pós-Graduação em Desenvolvimento Regional - Mestrado e Doutorado) - Universidade de Santa Cruz do Sul, Santa Cruz do Sul, 2008.

MATTAR, F. N. Pesquisa de marketing: metodologia, planejamento. 5. ed. São Paulo: Atlas, 1999. $1 \mathrm{v}$.

MINTZBERG, Henry; AHLSTRAND, Bruce; LAMPEL, Joseph. Safári de estratégia: um roteiro pela selva do planejamento estratégico. Porto Alegre: Bookman, 2000.

PAGLIUSO, Antonio Tadeu; CARDOSO, Rodolfo; SPIEGEL, Thais. Gestão organizacional: o desafio da construção do modelo de gestão. Instituto Chiavenato (Org.). São Paulo: Saraiva, 2010.

RAFFESTIN, Claude. Por uma geografia do poder. São Paulo: Ática, 1993.

SANTOS, Milton. O retorno do território. In: SANTOS, Milton et al. (Org.). Território: globalização e fragmentação. São Paulo: Hucitec/Anpur, 1994. p. 15-28.

Por outra globalização: do pensamento único à consciência universal. Rio de Janeiro:

Record, 2003. 


\section{ANEXO A}

\section{Questionário: Ciclo de vida nas organizações conforme Adizes, 2002}

Empresa:

A empresa foi constituída pelo sr(a), ou foi adquirida em funcionamento?

Quando a empresa foi fundada?

Quantos funcionários a empresa possui?

Qual é o número de pessoas envolvidas no negócio?

Quantas pessoas na empresa possuem o 3o grau ou mais?

A empresa investe em política de treinamento (cursos de capacitação e/ou qualificação profissional)?

A organização está engajada em algum programa de preservação ambiental?

Quais?

O estabelecimento possui envolvimento/participação em órgãos públicos ( PREFEITURA, ONG's, COMUD, COREDES, ACl, etc.)

Qual a origem de seus fornecedores e a distribuição percentual? ( )Município ( )Região ( )Do Estado ( )De outros Estados ( )Do País ( )Do Exterior

Qual a origem de seus clientes e a distribuição percentual? ( )Município ( )Região ( )Do Estado ( )De outros Estados ( )Do País ( )Do Exterior

\begin{tabular}{|c|c|c|c|c|c|c|}
\hline \multirow{2}{*}{\multicolumn{3}{|c|}{ Na sua opinião: os seguintes itens do questionário podem ser enquadrados como: }} & \multicolumn{2}{|c|}{ SIM } & \multicolumn{2}{|c|}{ NÃO } \\
\hline & & & \multirow[t]{2}{*}{ 1-informal } & \multirow[t]{2}{*}{ 2-formal } & \multirow[t]{2}{*}{ 1-ñ conhece } & \multirow[t]{2}{*}{ 2- tem conhec. } \\
\hline $\mathrm{a}$ & A1 & O empresário centraliza todas as decisões da empresa? & & & & \\
\hline $\mathrm{b}$ & B1 & A empresa conta com regras e procedimentos, mas geralmente o empresário necessita violá-las? & & & & \\
\hline $\mathrm{c}$ & $\mathrm{F}$ & Há procura para aquisição de suas ações e/ou interessados em sociedades na empresa? & & & & \\
\hline $\mathrm{d}$ & A & A empresa prioriza o produto? & & & & \\
\hline $\mathrm{e}$ & $\mathrm{C} 1$ & As diretrizes e/ou normas são sempre cumpridas pelos colaboradores da empresa? & & & & \\
\hline $\mathrm{f}$ & $\mathrm{D}$ & A organização possui orientação para satisfazer às necessidades dos clientes? & & & & \\
\hline g & A1 & O empresário percebe muita alienação pelas intervenções externas? & & & & \\
\hline $\mathrm{h}$ & G & Há formulação de estratégias de marketing? & & & & \\
\hline $\mathrm{i}$ & $\mathrm{H}$ & Seus sistemas funcionais são práticos e eficientes? & & & & \\
\hline $\mathrm{j}$ & A & Existe muita devolução de mercadoria e/ou retrabalho? & & & & \\
\hline $\mathrm{k}$ & $\mathrm{H}$ & A empresa tem compromisso/comprometimento com seus clientes? & & & & \\
\hline 1 & B & Há planejamento organizacional? & & & & \\
\hline $\mathrm{m}$ & $\mathrm{D}$ & Existe pouca discrepância entre o orçamento previsto e o realizado? & & & & \\
\hline o & $\mathrm{F}$ & A organização ajusta os preços de forma a compartibilizá-los com os custos? & & & & \\
\hline $\mathrm{p}$ & A1 & O empreendedor recebe amparo/apoio da família para desempenhar as suas atividades empresariais? & & & & \\
\hline
\end{tabular}




\begin{tabular}{|c|c|c|c|c|c|c|}
\hline & & \multirow[b]{2}{*}{ Na sua opinião: os seguintes itens do questionário podem ser enquadrados como: } & \multicolumn{2}{|c|}{ SIM } & \multicolumn{2}{|c|}{ NÃO } \\
\hline & & & 1-informal & 2-formal & 1-ñ conhece & 2- tem conhec. \\
\hline $\mathrm{q}$ & $\mathrm{F}$ & A empresa pensa em adquirir outras empresas para obter novos produtos e mercados? & & & & \\
\hline $\mathrm{r}$ & A & Geralmente é necessário trabalhar nos finais de semana e/ou feriados? & & & & \\
\hline $\mathrm{s}$ & $\mathrm{D}$ & As compras são efetuadas conforme as necessidades da empresa? & & & & \\
\hline $\mathrm{t}$ & $\mathrm{C} 1$ & O empresário precisa repensar a sua forma de gerir, delegar autoridade e transpor metas? & & & & \\
\hline $\mathrm{u}$ & $\mathrm{H}$ & A empresa gera recursos próprios para sua manutenção? & & & & \\
\hline $\mathrm{v}$ & B1 & O empresário já pode investir em carros, barcos, viagens de lazer e/ou outras formas de & & & & \\
\hline w & A & Existe controle formal de contas a pagar/receber? & & & & \\
\hline $\mathrm{x}$ & $\mathrm{E}$ & Há formalidade no tratamento e no vestir de seus dirigentes e colaboradores? & & & & \\
\hline $\mathrm{y}$ & B1 & A empresa conta com gerentes profissionais, administrativos ou herdeiros na sucessão & & & & \\
\hline $\mathrm{z}$ & $\mathrm{H}$ & A empresa está no mercado porque detém algum tipo de monopólio? & & & & \\
\hline aa & $\mathrm{C}$ & A empresa possui sistema administrativo estruturado? & & & & \\
\hline$a b$ & $\mathrm{H}$ & A empresa necessita de repasse de recursos financeiros do governo para cumprir suas obrigações? & & & & \\
\hline $\mathrm{ac}$ & A1 & A empresa possui liquidez para honrar seus compromissos em dia? & & & & \\
\hline $\mathrm{ad}$ & $\mathrm{E}$ & Ultimamente a empresa está diminuindo o valor investido em marketing? & & & & \\
\hline ae & $\mathrm{D}$ & O local de trabalho é improvisado conforme o crescimento da empresa? & & & & \\
\hline ag & G & A empresa é organizada? & & & & \\
\hline ah & $\mathrm{C}$ & Há profundidade gerencial? & & & & \\
\hline ai & G & A capacidade criativa da empresa está dirigida para a criação de produtos melhores? & & & & \\
\hline aj & B & Existe aumento expressivo nas vendas, sem esforço extra? & & & & \\
\hline ak & $\mathrm{E}$ & As mudanças são sempre bem-vistas e/ou aceitas? & & & & \\
\hline al & $\mathrm{D}$ & Os equipamentos (máquinas) pertencentes à empresa recebem manutenção somente quando estragam? & & & & \\
\hline am & G & Há muito conflito, muitas "facadas" pelas costas, muitas brigas internas? & & & & \\
\hline ao & A & Existe planejamento financeiro (objetivos/metas)? & & & & \\
\hline ap & $\mathrm{F}$ & Há constante preocupação com ameaça e concorrentes no mercado? & & & & \\
\hline aq & $\mathrm{E}$ & Existe acompanhamento rigoroso sobre o retorno do capital investido? & & & & \\
\hline ar & $\mathrm{C}$ & A empresa utiliza e monitora o fluxo de caixa? & & & & \\
\hline as & $\mathrm{B}$ & Possui posto de venda e/ou filiais em outras localidades? & & & & \\
\hline at & $\mathrm{C} 1$ & Há sistema de remuneração formal? & & & & \\
\hline $\mathrm{au}$ & A & Há livro-caixa formal? & & & & \\
\hline
\end{tabular}

COLÓQUIO - Revista do Desenvolvimento Regional - Faccat - Taquara/RS - v. 14, n. 2, jul./dez. 2017 


\begin{tabular}{|c|c|c|c|c|c|c|}
\hline \multirow{2}{*}{\multicolumn{3}{|c|}{ Na sua opinião: os seguintes itens do questionário podem ser enquadrados como: }} & \multirow{2}{*}{\multicolumn{2}{|c|}{ SIM }} & \multirow{2}{*}{\multicolumn{2}{|c|}{ NÃO }} \\
\hline & & & & & & \\
\hline av & $\mathrm{C}$ & Existe sistema de cumprimento de metas da empresa e dos colaboradores individualmente? & 1-informal & 2-formal & 1-ñ conhece & 2-tem conhec. \\
\hline aw & G & A empresa disponibiliza-se a vender sua reputação (tradição, marca, conhecimento, etc.)? & & & & \\
\hline $\mathrm{ax}$ & $\mathrm{B}$ & Existe planilha e/ou sistema para a formação do custo da mercadoria vendida? & & & & \\
\hline ay & $\mathrm{F}$ & Existe otimização do espaço físico da empresa? & & & & \\
\hline az & $\mathrm{E}$ & Os colaboradores disponibilizam grande parte de seu tempo para atender a clientes e/ou fornecedores? & & & & \\
\hline ba & $\mathrm{C} 1$ & Existe alta rotatividade de pessoas, especialmente dos indivíduos mais empreendedores? & & & & \\
\hline $\mathrm{bb}$ & $\mathrm{F}$ & A empresa investe e/ ou prioriza sistemas de controle, benefícios e instalações para o conforto? & & & & \\
\hline bc & $\mathrm{B}$ & Os colaboradores possuem liberdade para tomar decisões organizacionais? & & & & \\
\hline bd & B1 & Existe facilidade de o fundador delegar atribuições para seus colaboradores? & & & & \\
\hline be & $\mathrm{E}$ & Há grande expectativa de conquistar novos mercados, tecnologias e regiões inexploradas? & & & & \\
\hline bf & $\mathrm{C}$ & Existe alta rotatividade dos gerentes e/ou encarregados? & & & & \\
\hline bg & $\mathrm{H}$ & Seus colaboradores desempenham outras atividades paralelas? & & & & \\
\hline bh & $\mathrm{D}$ & A empresa possui indicadores de crescimento das vendas e da lucratividade? & & & & \\
\hline bl & B & Falta pessoal treinado (técnico) na empresa? & & & & \\
\hline bi & $\mathrm{C}$ & Os colaboradores são chamados por apelidos? & & & & \\
\hline bj & G & O fluxo de caixa, outrora positivo, agora torna-se negativo? & & & & \\
\hline
\end{tabular}

Fonte: Elaborado pelas autoras em junho de 2015, com base em Adizes (2002). 